\title{
Inovação e Sustentabilidade: proposta de política pública para o desenvolvimento de parque tecnológico voltado à sociobiodiversidade amapaense
}

\author{
Innovation and Sustainability: proposed public policy for the \\ development of technological park for the amapá sociobiodiversity
}

\author{
Márcio Luis Góes de Oliveira ${ }^{1}$ \\ José Erivan Ferreira Garçon ${ }^{2}$ \\ Robson Antonio Tavares Costa ${ }^{3}$ \\ ${ }^{1}$ Instituto Federal de Educação, Ciência e Tecnologia do Amapá, Brasil Novo, AP, Brasil \\ ${ }^{2}$ Centro de Gestão da Tecnologia da Informação, AP, Brasil \\ ${ }^{3}$ Universidade Federal do Amapá, Macapá, AP, Brasil
}

\begin{abstract}
Resumo
O Amapá ocupa a penúltima posição nos índices de competitividade entre os estados. Porém, compreende-se que o estado possui potencialidades que desenvolvidas de maneira sustentável podem reduzir o atraso econômico local. Assim, este estudo tem o propósito de propor uma política pública para a criação de um parque tecnológico no Amapá e, para tanto, analisará a relação sociobiodiversidade amapaense com as potencialidades de instituições científicas e tecnológicas, universidades e institutos de pesquisa. Como espaço, a pesquisa limitou-se aos municípios de Macapá e Santana, caracterizando-se como um estudo de caso, lançando mão da análise de indicadores socioeconômicos que demonstrassem o perfil regional. Baseado nos estudos realizados, foi proposto um fluxo com ações para a viabilização de um possível parque tecnológico no Amapá. Porém, verificou-se que, para a criação de um parque tecnológico no estado, é necessário que haja uma atividade econômica madura, com arranjos produtivos estruturados e atores articulados para o devido suporte aos empreendimentos.
\end{abstract}

Palavras-chave: Parque Tecnológico. Sociobiodiversidade. Instituições Científicas e Tecnológicas.

\begin{abstract}
Amapá occupies the penultimate position in the indexes of competitiveness among the states. However, it is understood that the state has potential that worked in a sustainable manner can reduce the local economic backwardness. Thus, this study aims to propose a public policy for the creation of a technology park in Amapá and to do so will analyze the Amapaense socio-biodiversity relationship with the potentialities of scientific and technological institutions, universities and research institutes. As a space the research was limited to the municipalities of Macapa and Santana, being characterized as a case study, using the analysis of socioeconomic indicators that demonstrated the regional profile. Based on the studies carried out, a flow of actions was proposed for the feasibility of a possible technology park in Amapá. However, it was found that for the creation of a technological park in the state there is a need for a mature economic activity, with structured productive arrangements and articulated actors for the proper support to the enterprises.
\end{abstract}

Keywords: Technologic Park. Sociobiodiversity. Scientific and Technological Institutions.

Área Tecnológica: Propriedade Intelectual. Inovação. Desenvolvimento. 


\section{Introdução}

O Amapá tornou-se Estado a partir da reforma de 1988 e ainda possui uma participação pouco expressiva na economia nacional. Segundo a Confederação Nacional da Indústria (CNI, 2017), por exemplo, o Estado participa com apenas $0,1 \%$ no Produto Interno Bruto (PIB) industrial nacional e, ainda, de acordo com o Centro de Liderança Pública (CLP, 2017), o Amapá ocupa a penúltima posição quando se avalia os índices de competitividade entre todos os estados brasileiros.

Porém, apesar de tais índices, compreende-se que o estado possui potencialidades que, desenvolvidas de maneira sustentável, podem reduzir o atraso econômico local. Destaca-se que o Amapá faz parte do maior sistema de biodiversidade do mundo, a Amazônia, possuindo um papel fundamental no ciclo hídrico e na emissão de carbono, além de possuir quase $20 \%$ de toda a água doce superficial do planeta, já que tem, segundo o Governo do Estado do Amapá (2009), 97\% de sua cobertura florestal original, demonstrando um grande potencial de uso sustentável da floresta.

Dessa forma, entende-se como fator relevante políticas públicas que visem mitigar as mazelas socioeconômicas locais através da simbiose entre empreendedorismo, inovação e o aproveitamento sustentável da sociobiodiversidade amapaense. Isto posto, visando propor alternativas para o desenvolvimento social e econômico, é que este estudo procurará relacionar a sociobiodiversidade amapaense com as potencialidades de instituições científicas e tecnológicas, universidades, institutos e com a iniciativa privada. Assim, este estudo propõe uma política pública para a criação de um parque tecnológico no estado do Amapá.

Segundo o Centro de Apoio ao Desenvolvimento Tecnológico (CDT/UnB, 2014), existem 94 iniciativas de parques tecnológicos no país, que já geraram mais de 32.200 empregos. Porém, na região Norte, segundo este mesmo estudo, apenas os estados do Amazonas, Pará e Rondônia possuem parques tecnológicos (total de cinco parques), porém, o Amapá ainda não conta com esta iniciativa.

Para o Centro de Apoio ao Desenvolvimento (CTB/UnB, 2013), parques tecnológicos são instituições que promovem infraestrutura técnica, logística e administrativa para o apoio à competitividade de pequenas empresas, favorecendo a transferência de tecnologia e a criação de ambiente propício à inovação. No mesmo sentido, Spolidoro e Audy (2008) entendem que:

Parque Tecnológico é uma organização gerida por profissionais especializados, que têm por objetivo fundamental aumentar a riqueza da comunidade na qual estão inseridos por meio da promoção da cultura da inovação e da competitividade das empresas e das instituições intensivas em conhecimento associadas à organização.

A norma legal nacional, conhecida também como o novo marco legal de ciência, tecnologia e inovação ou Lei n. 13.243, de 11 de janeiro de 2016, também conceitua parque tecnológico, afirmando que se trata de complexo planejado de desenvolvimento empresarial e tecnológico, promotor da cultura de inovação, da competitividade industrial, da capacitação empresarial e da promoção de sinergias em atividades de pesquisa científica, de desenvolvimento tecnológico e de inovação, entre empresas e ICTs. 
No contexto internacional também há entendimentos sobre a conceituação e o funcionamento de parques tecnológicos. A International Association of Science Parks (IASP, 2016), por exemplo, afirma que os parques tecnológicos são organizações geridas por profissionais especializados, que objetivam o desenvolvimento socioeconômico da comunidade e a promoção da cultura da inovação e da competitividade das empresas intensivas em conhecimento.

Falando em contexto internacional, verifica-se que quanto à gênese dos parques tecnológicos, ela ocorreu na década de 1950 no Vale do Silício, no estado da Califórnia, Estados Unidos, região hoje referência em empreendedorismo de base tecnológica e ecossistemas de inovação. Já na Europa e na Ásia, a década de 1970 foi o marco inicial (VEDOVELLO, 2000).

Corroborando com a importância da análise e do aprendizado a partir das experiências, Zouain e Plonski (2006) dizem que como a etapa inicial de um processo de implantação de parque tecnológico, a busca por referências em experiências nacionais e internacionais é fator de grande importância para o sucesso na criação e estruturação de parques tecnológicos. Esses autores construíram seis etapas que entenderam ser de grande relevância no processo de criação e consolidação de parques tecnológicos, a saber: a) conceituação e caracterização de parque tecnológico; b) realização da análise da região; c) caracterização do mercado e vocação da região; d) elaboração de masterplan conceitual; e) verificação de viabilidade econômico-financeira; e f) animação e articulação.

Outra questão são as tipologias e as gerações de parques tecnológicos, que apontam o "modus operandi" dessas experiências. O entendimento de como funcionam os parques é importante, pois, para a instalação desse complexo instrumento, é necessário que ele esteja harmonicamente ligado às características da região na qual se pretende instalá-lo. Segundo estudos da Associação Brasileira de Desenvolvimento Industrial (ABDI) e da Anprotec (2008), foram identificadas três gerações de parques tecnológicos em função de suas características.

A primeira geração refere-se a um modelo chamado de science push. Um modelo originalmente americano, mas que influenciou tanto a Europa quanto o Japão. Essa tipologia caracteriza-se por estar vinculada a uma região já vocacionada para o empreendedorismo e inovação, e com grande desenvolvimento socioeconômico local.

Já a segunda geração chamada de demand pull, mais madura que a primeira geração, pois não foi gerada de maneira espontânea como a primeira, possui forte relação empresarial, com maior independência do setor público e gerada para replicar as melhores práticas das primeiras experiências de parques tecnológicos (primeira geração). A Cambridge Science Park, no Reino Unido, e a Sophia Antipolis, na França são algumas das experiências desse tipo de parque.

Por fim o terceiro modelo, caracterizado por ser uma experiência utilizada em países em desenvolvimento, busca absorver experiências das duas primeiras gerações, conta com grandes investimentos estatais e possui como foco o desenvolvimento urbano, regional e ambiental.

Os parques tecnológicos possuem entre suas características o respeito e a busca pelo fortalecimento das vocações regionais. Assim, todo o investimento com infraestrutura, recursos humanos, logística, crédito, etc. deve propor que o fim seja o fortalecimento socioeconômico local.

Dessa forma, as tipologias dos parques tecnológicos estão vinculadas às características da região onde estão instaladas. Paladino e Medeiros (1997) realizaram uma comparação entre os antigos distritos industriais com a ideia de parques tecnológicos, eles afirmaram que os primeiros eram apenas criar um composto de empresas reunidas em um espaço físico, enquanto os 
parques tecnológicos são "habitats da inovação" que renovam os conceitos e as técnicas antes aplicados na indústria tradicional, promovendo a interação entre a academia $e$ as indústrias $e$ estimulando os jovens ao empreendedorismo.

No país ainda existem poucas experiências de parques tecnológicos com forte dedicação ao fortalecimento das biodiversidades regionais. Na Amazônia, há algumas experiências que bem estudadas podem se tornar importantes "benchmarkings" para a aplicação local. Um dos exemplos é o Parque Científico e Tecnológico para Inclusão Social (PCTIS) da Universidade Federal do Amazonas (UFAM).

Trata-se de um parque que, atualmente, conta com mais de 80 projetos cadastrados e mais de 1.300 pesquisadores em atuação e que tem como objetivo o desenvolvimento de ações de inovação tecnológica e social que resultem no desenvolvimento com foco na biodiversidade e no adensamento de arranjos produtivos e inovativos locais, sendo que o público-alvo são os povos tradicionais.

Outra experiência regional é o Parque de Ciência e Tecnologia Guamá (PCT Guamá), sediado na cidade de Belém, PA. Com uma área de $720.000 \mathrm{~m}^{2}$, é o primeiro parque tecnológico a entrar efetivamente em operação na Amazônia e, atualmente, além da biotecnologia, tecnologia ambiental e mineral, o PCT Guamá também possui empreendimentos na área de tecnologia da informação e comunicação.

Verifica-se, pois, que os parques até agora citados não desenvolvem apenas produtos da sociobiodiversidade amazônica, porém há um nicho considerável de empreendimentos e de instituições de pesquisa dedicadas a este ramo.

Uma outra experiência a ser destacada é a BioTec-Amazônia. Não se trata de um parque tecnológico, mas de uma experiência de associação de direito privado, localizada dentro de um parque tecnológico, e é dedicada exclusivamente para a promoção do uso sustentável da biodiversidade estadual e regional. Essa associação também está localizada no Parque de Ciência e Tecnologia Guamá (PCT Guamá) e foi criada para gerir o programa paraense de incentivo ao uso sustentável da biodiversidade amazônica. Verifica-se, dessa forma, a importância da biodiversidade amazônica como recurso para o desenvolvimento socioeconômico local.

No estado do Amazonas há uma relevante experiência, trata-se do Parque Tecnológico de Manaus (ManausTec). Com uma área de quase $299 \mathrm{mil} \mathrm{m}^{2}$, o ManausTec possui como missão criar um ambiente inovador que aproveite as potencialidades do Amazonas e gere riqueza a partir de produtos de alto valor agregado. A proximidade da biodiversidade amazônica e a forte relação com centros de pesquisas como INPA, UFAM, UEA e Instituto Genius é um fator considerável, além de estar em um dos principais polos industriais do país.

\section{Metodologia}

A abordagem ao problema deste estudo se deu de maneira qualitativa, possui o caráter descritivo, que, como afirma Almeida (2012), se trata da exposição das particularidades de determinada população, sendo que a padronização, quanto ao uso de técnicas de coletas de dados, está entre as principais características dessa tipologia.

Para o desenvolvimento deste estudo, realizou-se inicialmente a fundamentação teórica a partir de revisão bibliográfica e documental tendo como escopo os parques tecnológicos, sua conceituação, os fatores fundamentais para a sua criação, a caracterização da região onde se 
propõe a instalação dos parques, os potenciais produtivos (da biodiversidade amapaense) e as possíveis instituições componentes dessa estrutura.

Como espaço geográfico a ser pesquisado, limitou-se aos municípios de Macapá e Santana, caracterizando a presente pesquisa como um estudo de caso, já que, para Gil (2008), trata-se de uma investigação de um ou de alguns objetos de pesquisa, de forma que possibilite sua compreensão por inteiro.

Para a proposição de políticas públicas para a criação de um parque científico e tecnológico no estado do Amapá, tomou-se como norte teórico Zouain e Plonski (2006). Eles apontam seis etapas determinantes para a viabilização de um parque tecnológico, sendo que esta pesquisa realizará três dessas etapas, a saber: a) conceituação e caracterização de parque tecnológico; b) realização da análise da região; e c) caracterização do mercado e vocação regional. Além dos teóricos mencionados, também foram utilizados como referência para a construção da política Bellavista e Sanz (2009), pois eles já elencaram cinco fatores críticos de sucesso para um parque tecnológico, a saber: prestígio do parque, localização, ligação com universidades e institutos de pesquisa, suporte institucional e demanda local.

Para a caracterização da região onde se localizam os Municípios de Macapá em Santana, lançou-se mão da análise de estudos e indicadores socioeconômicos que demonstrassem o perfil da região, buscando estruturar a proposta de política pública para a criação de um parque científico e tecnológico no estado do Amapá. Para o detalhamento da política pública proposta, serão realizadas tanto a descrição textual quanto elementos gráficos, como fluxogramas e imagens. A região de Macapá e Santana foi escolhida em virtude de se tratar da área de maior desenvolvimento populacional e econômico do Estado, pois é a porta de entrada do setor produtivo local, localizando-se as principais instituições científicas e tecnológicas, entidades de fomento, empresas e todo o arcabouço para o desenvolvimento de uma região.

\section{Resultados e Discussão}

Serão, pois, detalhados os resultados reativos à pesquisa, tendo como escopo a construção de proposta para a implantação de um parque científico e tecnológico no estado do Amapá. Para tanto levar-se-ão em consideração os norteadores teóricos mencionados na metodologia.

\section{Conceituação e Caracterização de Parque Tecnológico}

Esta etapa da pesquisa segue um roteiro desenvolvido por Zouain e Plonski (2006), que apontaram seis etapas determinantes para a viabilização de um parque tecnológico, aqui será realizada a primeira ação de conceituar e de caracterizar os parques tecnológicos.

Para Zouain e Plonski (2006), antes das etapas seguintes para a implantação de um Parque Tecnológico, é preciso entender o significado dessas experiências buscando o aprendizado tanto com experiências nacionais quanto com as de outras nações. Nessa fase, deve-se realizar o levantamento bibliográfico e a revisão da literatura existente, fazer visitas in loco para buscar um benchmarking com boas práticas de gestão de parques tecnológicos e procurar por capacitações com especialistas na área. 
Tendo em vista, porém, de nesta pesquisa já foi realizada a revisão da literatura com a conceituação de parques tecnológicos, a presente pesquisa seguirá para a próxima etapa determinante para a implantação de parques científicos e tecnológicos.

\section{Realização da Análise da Região}

O estado do Amapá, como membro do maior sistema de biodiversidade do mundo, a Amazônia, é conhecido por ser rico em recursos naturais. Porém, a utilização sustentável desses recursos para o desenvolvimento socioeconômico local também já é há tempos objeto de discussões.

Um dos marcos da preocupação com a preservação dos recursos naturais amapaenses foi a instituição das primeiras unidades de conservação no estado, que, segundo Porto e Brito (2005), ocorreu a partir de 1980, com a principal preocupação da exploração do manganês no estado. As duas primeiras unidades de conservação criadas no Amapá foram o Parque Nacional do Cabo Orange, que fica entre os municípios de Oiapoque e Calçoene, e a Reserva Biológica do Lago Piratuba, localizada no município de Amapá. Atualmente, o estado possui um total de 19 unidades de conservação e cinco Terras Indígenas homologadas, resultando em mais de 10 milhões de hectares de terra protegida (FIGUEIREDO, 2015).

Depreende-se, pois, que o fato de o Amapá possuir a maior parte de sua extensão territorial composta de áreas protegidas, o que é compreendido como um dos fatores justificadores do incipiente desenvolvimento econômico do estado. Entendimento este que Porto e Brito (2005) já tinham, quando afirmavam que o grande percentual de terras protegidas seria um dos resultantes da fraca dinâmica do setor produtivo local. Segue a Figura 1 com a descrição das áreas protegidas (unidades de conservação e terras indígenas) do estado do Amapá.

Figura 1 - Descrição das Terras protegidas do Amapá

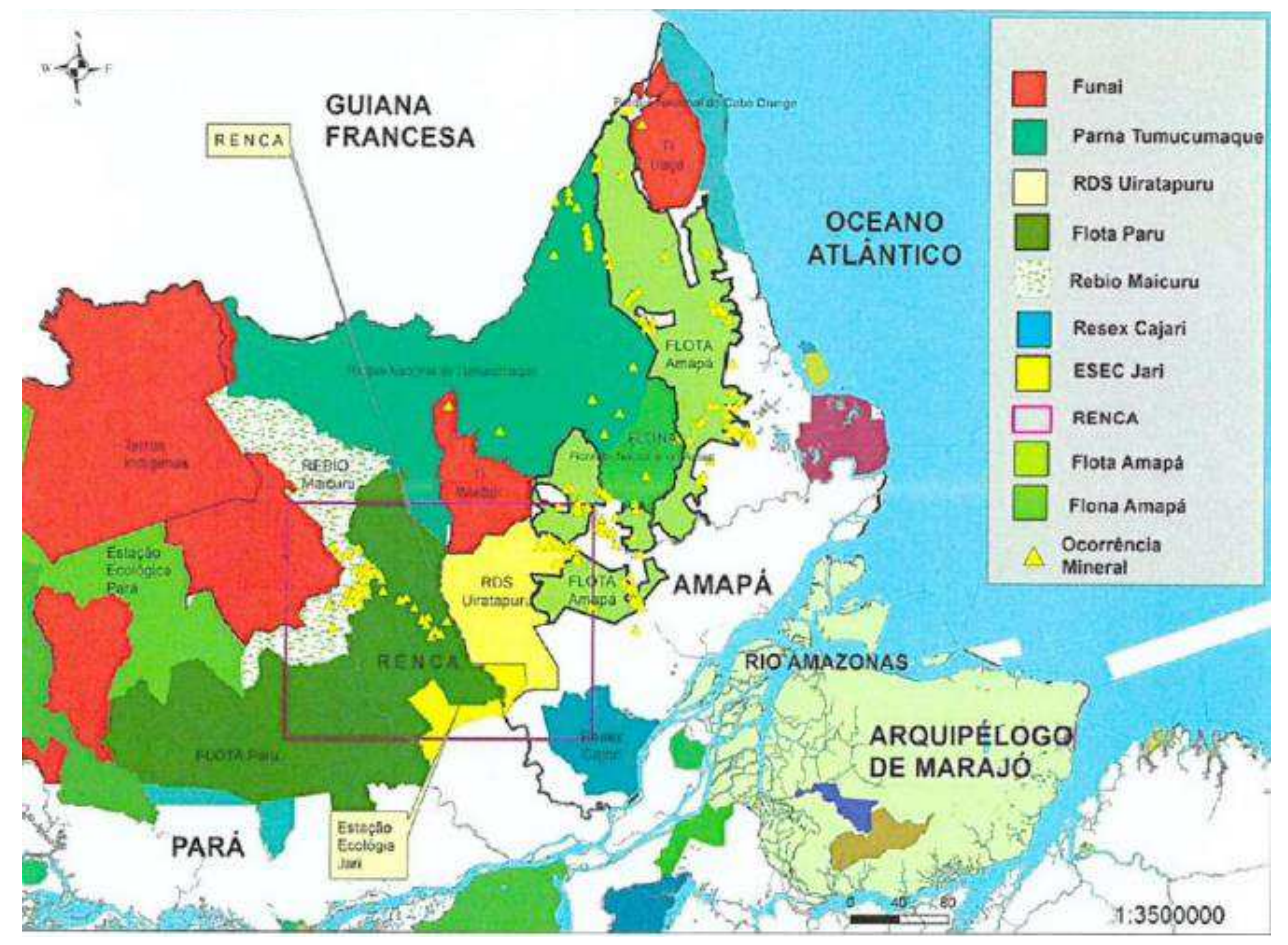

Fonte: Ministério de Minas e Energia (2017) 
Entende-se, porém, que o aproveitamento sustentável do conhecimento tradicional associado e da sociobiodiversidade amapaense é uma das opções para o incremento da economia. Assim, a biotecnologia, a farmacologia, a indústria de cosméticos e os demais ramos tecnológicos associados à exploração racional dos recursos naturais amapaenses seriam uma alternativa para o desenvolvimento socioeconômico da região.

Miguel (2007) corrobora com a ideia doa importância do aproveitamento econômico e sustentável da biodiversidade amazônica, mas pede atenção afirmando ser imprescindível analisar se as cadeias produtivas de cosméticos e fitoterápicos estão promovendo a expansão e a modernização das empresas e das comunidades extrativistas e produtoras.

Outro ponto relevante é sobre a possível localização do parque tecnológico proposto. Entre as cidades de Macapá e Santana, além de localizar-se o distrito industrial, há também dois Campi de instituições federais de ensino, a saber: Instituto Federal de Educação, Ciência e Tecnologia do Amapá (IFAP/Campus Santana) e da Universidade Federal do Amapá (UNIFAP/ Campus Santana).

Destarte, no distrito industrial da Santana, AP, poderia ser disponibilizado espaço para a instalação de ICTs, institutos de pesquisa e, claro, de empresas de base tecnológica. Porém, apesar de possuir localização privilegiada, ligando os dois maiores municípios do estado do Amapá, o IBGE (2018) afirma que o Distrito Industrial de Santana, por exemplo, ainda não dispõe de infraestrutura necessária ao seu bom desempenho.

Apesar de a referência ser do ano de 2004, o distrito industrial de Santana, AP, ainda não contou com um pujante desenvolvimento. No entanto, dada a localização estratégica para a instalação de empreendimentos, políticas públicas para o estímulo ao desenvolvimento daquele espaço seriam um fator determinante para a futura instalação de um parque tecnológico naquele perímetro. Ainda, soma-se a isso a possibilidade de investimento estatal, ou por meio de Parceria Público Privada (PPP) para o incremento do distrito industrial, fornecendo, assim, as condições para a instalação de um possível parque tecnológico.

\section{Caracterização do Mercado e Vocação Regional}

É sabido que o Amapá é uma região importante, tanto pelas suas riquezas naturais quanto por sua localização geográfica, estando ladeado na fronteira ao norte com a Guiana Francesa, um departamento ultramarino da França, além de possuir um porto (no Município de Santana), sendo estratégico entreposto de escoamento de produtos.

Outra questão a ser considerada é a área de livre comércio de Macapá e Santana (ALCMS), criada pela Lei n. 8.387, de 30 de dezembro de 1991, e que visa ao desenvolvimento das cidades que possuem fronteiras internacionais localizadas na Amazônia Ocidental. O instrumento utilizado por dispositivo legal foi o do oferecimento de benefícios fiscais que se assemelham aos disponibilizados à Zona Franca de Manaus, principalmente quanto ao Imposto sobre Produtos Industrializados (IPI) e ao Imposto sobre Circulação de Mercadorias e Prestação de Serviços (ICMS) (BRASIL, 1991). 
O mercado amapaense ainda é incipiente com relação à atividade industrial, caracterizando-se por possuir forte atuação do setor de comércio e serviços, com grande dependência dos recursos advindos da folha de pagamento do funcionalismo público (federal, estadual e municipal), o que ficou conhecido como a "economia do contracheque". Segue o Gráfico 1 com a demonstração do percentual de participação do setor primário (agricultura e extrativismo), secundário (indústrias) e terciário (comércio e serviços) na atividade econômica amapaense.

Gráfico 1 - Composição Setorial na Economia Amapaense

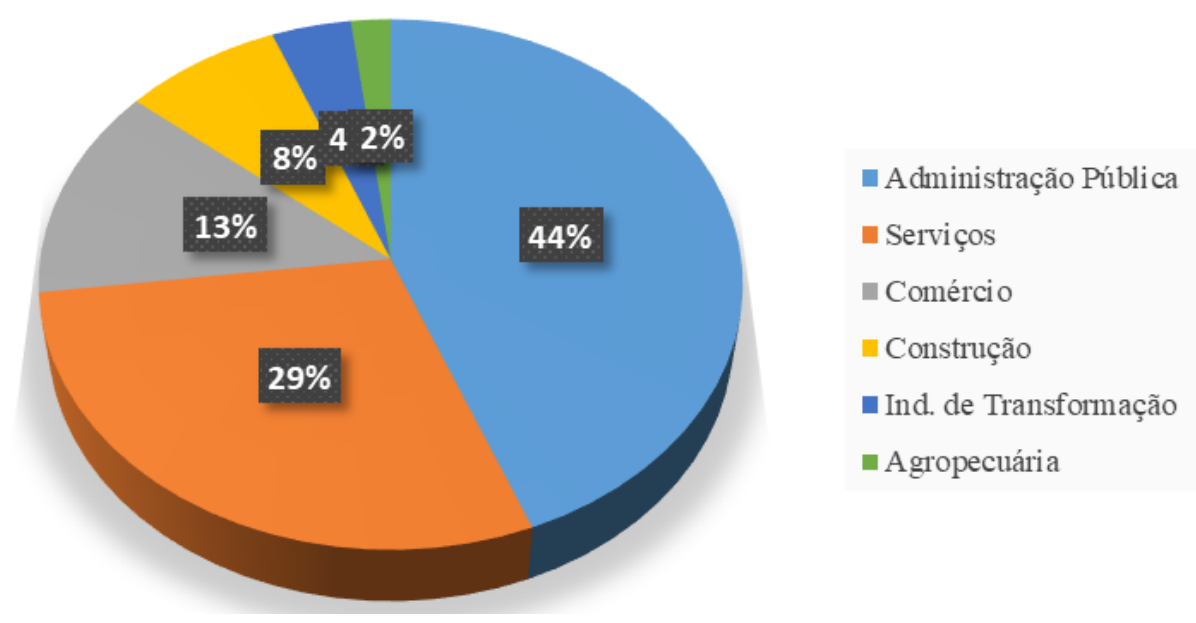

Fonte: IBGE (2019)

Verifica-se, pois, com o Gráfico 1 que a participação tanto agrícola quanto industrial na economia do estado ainda é incipiente, ficando a cargo da administração pública e do setor de comércio e serviços o maior percentual de participação. Assim, entende-se que um parque tecnológico poderia ser uma opção de incremento econômico local, desde que haja uma política pública que articule a participação tanto de instituições científicas e tecnológicas, quanto da iniciativa privada por meio da exploração das vocações regionais.

Apesar dos números, observa-se uma mudança no contexto tanto no setor agrícola quanto na atividade industrial. O estado, a partir de 2012, passou a iniciar a inserção no circuito produtivo da soja, o que pode representar um incremento no setor agroindustrial amapaense (IBGE, 2018). Segundo Margarit (2017), capitais privados têm sido investidos em compra de terras, equipamentos e insumos, sendo inclusive criada a Associação dos Produtores de Soja do Estado do Amapá (APROSOJA).

Apresenta-se o Gráfico 2 com a descrição das áreas por hectare utilizadas para a produção de grãos no estado do Amapá no período safra 2015/2016. 
Gráfico 2 - Áreas de produção de grãos período 2015-2016

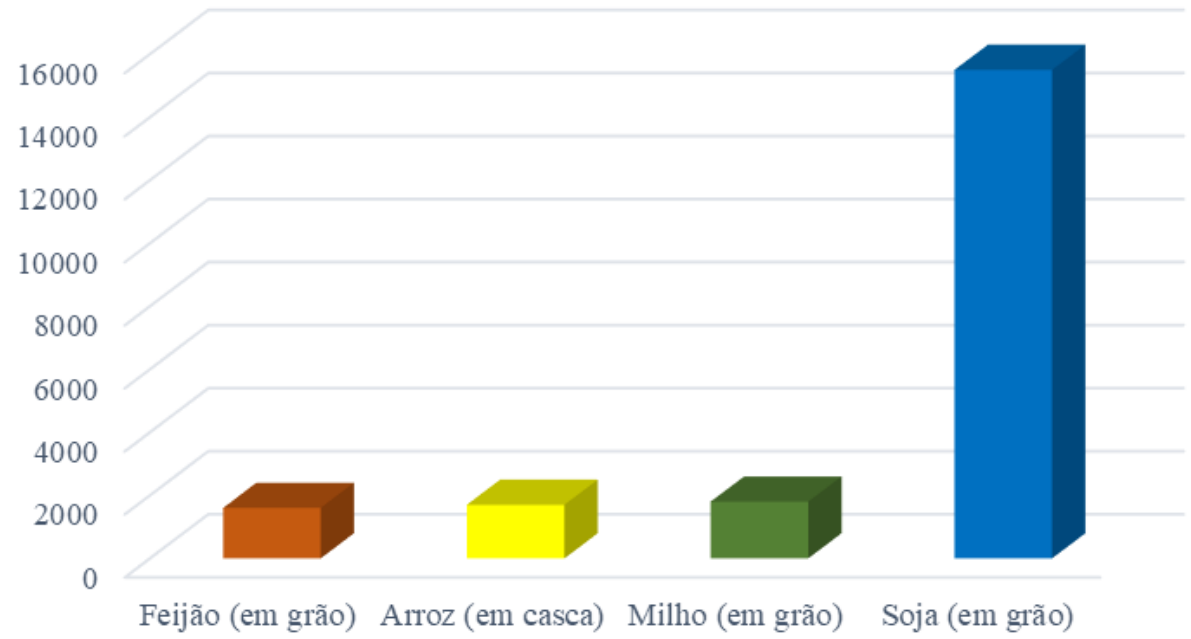

Fonte: IBGE (2018)

Percebe-se que a produção de soja vem ganhando destacada escala, o que é indicativo de uma mudança de contexto quanto aos aspectos da produção agroindustrial do estado do Amapá.

Como caracterização regional, compreende-se que as tratativas sobre políticas que estão ou deveriam estar em processo de viabilização são um ponto a ser ajustado. Como exemplo, é possível citar as Zonas de Processamento de Exportações (ZPEs). Institucionalizadas em 1988 ainda no governo José Sarney, por meio do Decreto n. 2.452, de 29 de julho de 1988 (SILVA et al., 2014), essas são áreas de livre comércio com o mercado externo, com o objetivo de viabilizar a instalação de empresas com viés para a exportação. Ainda segundo Silva et al. (2014), a atração de investimentos estrangeiros e a difusão tecnológica para o desenvolvimento econômico e social do país estão entre os objetivos desta política.

Para a viabilização das ZPEs, o estado brasileiro (tanto o governo federal quanto os estaduais) lançam mão de diversas ações de estímulo, como incentivos fiscais, concessão de espaços para a instalação de indústrias, etc. Especificamente com relação à atividade de pesquisa científica $e$ tecnológica, as ZPEs fornecem incentivos ligados aos dispêndios realizados em P\&D. Porém, no Amapá, esse processo ainda não "saiu do papel”. Segundo o Sebrae (2019), a ZPE do Amapá, quando em funcionamento, pretende se tornar um polo industrial com incentivos fiscais, estimulando especificamente a exportação de grãos, pescado beneficiado e derivados da madeira.

Entende-se que as ZPEs não seriam concorrentes dos parques tecnológicos, mas fazem parte deles. A diferença é que com as ZPEs dentro do parque, as instituições de pesquisa, universidades, institutos federais e escolas técnicas fariam parte como arranjos voltados para o desenvolvimento da ciência e da tecnologia associada ao desenvolvimento industrial para exportação. Porém, como afirma o Sebrae (2019), o Amapá é a Unidade da Federação mais atrasada nesse processo.

O Quadro 1 traz a descrição das ZPEs já instaladas no país. 
Quadro 1 - Lista de ZPEs institucionalizadas no Brasil

\begin{tabular}{|c|c|c|c|}
\hline N. & NOME DA ZPE & N. & NOME DA ZPE \\
\hline 1 & ZPE de Ilhéus (BA) & 13 & ZPE de Suape (PE) \\
\hline 2 & ZPE de Araguaína (TO) & 14 & ZPE do Sertão (RN) \\
\hline 3 & ZPE de Cáceres (MT) & 15 & ZPE de Macaíba (RN) \\
\hline 4 & ZPE de Barcarena (PA) & 16 & ZPE do Ceará (CE) \\
\hline 5 & ZPE de São Luís (MA) & 17 & ZPE de Parnaíba (PI) \\
\hline 6 & ZPE de Rio Grande (RS) & 18 & ZPE de Bataguassu (MS) \\
\hline 7 & ZPE de Corumbá (MS) & 19 & ZPE de Boa Vista (RR) \\
\hline 8 & ZPE de Vila Velha (ES) & 20 & ZPE do Acre (AC) \\
\hline 9 & PE de Imbituba (SC) & 21 & ZPE de Aracruz (ES) \\
\hline 10 & ZPE de João Pessoa (PB) & 22 & ZPE de Barra do Coqueiro (SE) \\
\hline 11 & ZPE de Teófilo Otoni (MG) & 23 & ZPE de Fernandópolis (SP) \\
\hline 12 & ZPE de Itaguaí (RJ) & 24 & ZPE de Uberaba (MG) \\
\hline & & 25 & ZPE de Porto Velho (RO) \\
\hline
\end{tabular}

Fonte: Dados da Pesquisa (2019)

Observa-se no Quadro 1 que das 25 ZPEs institucionalizadas, cinco estão na região Norte. Entende-se, assim, que a efetiva operacionalização das ZPEs seria fator importante para o desenvolvimento socioeconômico do estado e um integrante fundamental como trabalho "consorciado" a um possível parque científico e tecnológico.

Destarte, perpassadas as três primeiras etapas propostas por Zouain e Plonski (2006) para a implantação de parques tecnológicos, será realizada a descrição de algumas experiências de parques tecnológicos que possuem entre o escopo de funcionamento o fortalecimento da biodiversidade local. Na sequência, será realizada a sugestão de política pública de articulação de criação de um parque tecnológico entre as cidades de Macapá e Santana, tomando, agora, por base os estudos de Bellavista e Sanz (2009), com os cinco fatores críticos de sucesso para um parque tecnológico: prestígio do parque, localização, ligação com universidades e institutos de pesquisa, suporte institucional e demanda local.

\section{Proposta de Política Pública para a Criação de um Parque Tecnológico no Amapá}

Assim, depois de fundamentar teoricamente o presente estudo, tomando por base os estudos de Zouain e Plonski (2006) quanto às etapas de implantação de parques tecnológicos, será discutida a proposta de política pública para a criação de um parque tecnológico no Amapá. Levando agora em consideração os estudos realizados por Bellavista e Sanz (2009), que elenca- 
ram cinco fatores críticos de sucesso para um parque tecnológico, a saber: prestígio do parque, localização, ligação com universidades e institutos de pesquisa, suporte institucional e demanda local. Tendo em vista, ainda, tratar-se de uma proposta, o primeiro fator crítico, prestígio do parque, não será objeto do estudo.

Dessa forma, serão tratados cada item dos referidos critérios, sugerindo-se ações ou apontando atores que podem viabilizar a operacionalização do parque no estado do Amapá.

\section{Ligação com Universidades e Institutos de Pesquisa e Suporte Institucional}

Atualmente, no Amapá, há duas instituições científicas e tecnológicas federais em atuação: a Universidade Federal do Amapá (UNIFAP) e o Instituto Federal de Educação, Ciência e Tecnologia do Amapá (IFAP). De acordo com Abreu et al. (2016), parques tecnológicos são instituições criadas para promover fluxos de conhecimento na interação entre empresas e Instituições Científicas e Tecnológicas (ICTs), resultando em desenvolvimento econômico e tecnológico. Assim, entende-se que a participação "consorciada" entre IFAP e UNIFAP seria um dos pontos relevantes para que houvesse a simbiose da tríplice hélice para a inovação $e$ desenvolvimento local.

Nessa proposta de atuação conjunta, laboratórios, corpo de pesquisadores, Núcleos de Inovação Tecnológica (NITs), incubadoras e outros ambientes promotores de inovação dessas duas instituições poderiam trabalhar de maneira associada, procurando mitigar suas limitações de recursos humanos, financeiros e de infraestrutura.

Criada em 2006, entende-se que a Universidade do Estado do Amapá (UEAP) seria um relevante instrumento como "player" de um possível parque científico e tecnológico no estado. Segundo a Lei n. 966, de 31 de maio de 2006, a UEAP possui entre as missões institucionais a potencialização da biodiversidade do estado, procurando transformá-la em oportunidades de negócios por meio da geração de novos conhecimentos e tecnologias.

A UEAP possui cursos voltados para o desenvolvimento da sociobiodiversidade regional, como: engenharia de pesca, engenharia florestal, de produção, engenharia ambiental, licenciatura em ciências naturais, entre outros. Assim, entende-se que, com o corpo de docentes e discentes pesquisadores, laboratórios e toda a infraestrutura da instituição poderiam ser mais um dos protagonistas no processo de desenvolvimento científico e tecnológico estadual.

O Instituto Estadual de Pesquisas Científicas e Tecnológicas (IEPA), referência estadual na realização de pesquisas científicas e tecnológicas, com a utilização de recursos da sociobiodiversidade amapaense, seria uma outra instituição que poderia fazer parte do rol de Instituições Científicas e Tecnológicas (ICTs) que poderiam participar da estrutura de um parque tecnológico no Amapá.

Criada em 2009 e vinculada à Secretaria de Estado da Ciência e Tecnologia (SETEC/AP), atualmente, o IEPA possui em seu quadro funcional 11 doutores e 27 mestres com expertise em diversas áreas relacionadas à biodiversidade amapaense, como fitoterapia, pesquisas aquáticas, pesquisas museológicas, entre outras, além de possuir a única incubadora de empresas do estado (IEPA, 2019). 
Além das instituições científicas e tecnológicas estaduais já citadas, por meio de observação participante, verifica-se que o executivo estadual possui outras instituições que poderiam formatar um rol de "players" para atuação no parque científico e tecnológico, a saber: Agência de Fomento do Amapá (AFAP), para atuação no microcrédito, Fundação de Amparo à Pesquisa (FAPEAP) para o financiamento de projetos de pesquisa a serem desenvolvidos, Secretaria de Estado do Trabalho e Empreendedorismo (SETE) para a capacitação e fomento de microempreendedores, etc.

Um outro "player" que pode tornar exequível a criação de um parque tecnológico no Amapá é o poder legislativo local, sendo tanto o estadual quanto o municipal. Um dos grandes exemplos de atuação legislativa foi a aprovação no dia 4 de abril de 2018 do Marco Estadual de Ciência, Tecnologia e Inovação. De iniciativa do poder executivo estadual, mas aprovado de maneira unânime pela Assembleia Legislativa do Amapá, a Lei n. 2.333/2018 dispõe como os agentes públicos estaduais poderão atuar como promotores do sistema estadual de ciência tecnologia e inovação e fortalecimento do ambiente produtivo estadual (AMAPÁ, 2018). Nessa norma legislativa, constam questões como: modalidades de incentivos à pesquisadores, inventores e empreendedores para a inovação e sobre estímulo à criação e fortalecimento de ambientes promotores da inovação, como é o caso dos parques tecnológicos. Assim, consta em Amapá (2018, art. 32) que:

O Governo do Estado do Amapá, por meio do CONSECTI deverá estabelecer as políticas para a criação e fortalecimento de parques tecnológicos, incubadoras de empresas e outros ambientes de inovação como parte de sua estratégia para incentivar os investimentos em inovação, pesquisa científica e tecnológica, que gerem novos negócios, trabalho e renda e ampliem a competitividade da economia amapaense e o desenvolvimento tecnológico do ambiente produtivo, socioambiental e da biodiversidade do Estado.

Assim, seguindo o que pensam Vilà e Pagès (2008), os parques tecnológicos devem promover o desenvolvimento regional e estimular parcerias tecnológicas entre academia e empresas e o fortalecimento de empresas de base tecnológica.

\section{Demanda Local}

Rowe e Commins (2008) afirmavam que, para o sucesso de um parque tecnológico, uma das questões fundamentais é que este esteja em uma região de economia expressiva, diversificada e bem estabelecida; com uma forte base de pesquisa; cultura de empreendedorismo; ${ }^{1}$ stakeholders, incluindo universidade e centro de pesquisa, engajados ativamente em liderar e dedicar recursos para estabelecer o parque tecnológico e gerenciamento proativo e empreendedor.

Entende-se que o Amapá é um estado em desenvolvimento, e que ainda está por organizar as estratégias de valorização das vocações regionais para a construção efetiva de clusters para o desenvolvimento de nichos específicos. Porém, o conhecimento tradicional associado, a sociobiodiversidade amapaense e a existência de ICTs federais e estaduais com um crescente número de pesquisadores mestres e doutores, além de possuir espaços como o distrito industrial e expectativas da efetiva implantação de uma Zona de Processamento de Exportações, além

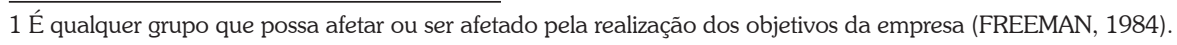


da Zona Franca Verde, podem ser panos de fundo para a viabilização de um parque científico e tecnológico no Amapá.

Assim, entre os fatores críticos citados por Bellavista e Sanz (2009), verifica-se que a organização da demanda local e o entendimento das vocações regionais com relação ao aproveitamento dos produtos e serviços advindos da sociobiodiversidade local constam entre as ações para a construção das estratégias de implantação de um parque científico e tecnológico no Estado do Amapá.

Baseada nos estudos dos fatores críticos citados por Bellavista e Sanz (2009), segue a Figura 2 com o fluxo proposto para as ações de articulação para que seja viabilizada a criação de um parque tecnológico no estado do Amapá.

Figura 2 - Proposta de Fluxo de articulação de ações para criação do PCT no Amapá.

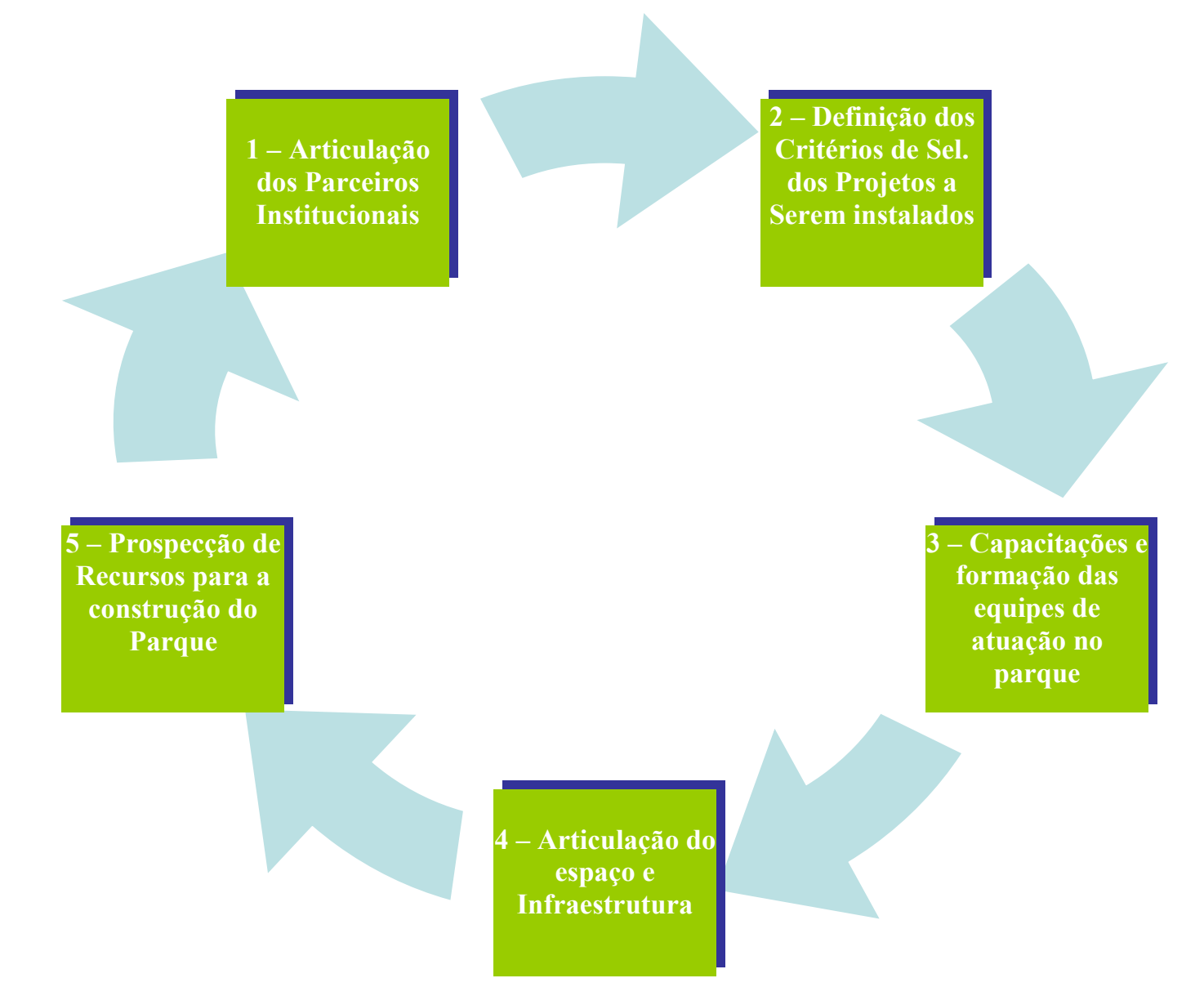

Fonte: Dados da Pesquisa (2019)

A Figura 2 demonstra de maneira simplificada o processo de articulação de acordo com a política pública proposta no presente estudo. Não se vislumbra esgotar todos os embasamentos teóricos ou práticas para a implementação desta política, e nem afirmar categoricamente que o estado do Amapá já possua as condições econômicas e de infraestrutura para a existência de um parque científico e tecnológico na região, mas demonstrar quais os atores seriam necessários para esse processo e quais os caminhos para que tal política seja empreendida. 


\section{Considerações Finais}

Esta pesquisa não teve como intento esgotar todas as possibilidades de ações para a instalação de um parque tecnológico no Estado do Amapá, porém, buscou contribuir apontando alternativas, direcionamentos para ações articuladas, para mitigar o "gap" do desenvolvimento local.

Com o estudo, verificou-se que há um arcabouço de ações exequíveis e que articuladas a contento poderia subsidiar a criação e a consolidação de um parque tecnológico no estado do Amapá.

Como verificado no estudo para a implantação de um parque tecnológico, há a necessidade de uma atividade econômica madura, com arranjos produtivos estruturados e atores articulados para o devido suporte aos empreendimentos. Quando se fala em suporte, trata-se de diversos âmbitos, como financiamento, suporte em propriedade intelectual e transferência tecnológica, apoio à gestão etc.

Como sugestão para novos estudos, propõe-se a análise das estratégias para a difusão e transferência das tecnologias desenvolvidas pelas empresas atuantes nos parques tecnológicos; ações para o apoio à internacionalização das firmas residentes, e sobre planejamento estratégico para as instituições científicas e tecnológica. Por fim, deseja-se que este estudo tenha contribuído para a maior compreensão quanto ao funcionamento dos parques tecnológicos, principalmente no que suscita à clarificação das reais possibilidades de instalação de um parque cientifico $e$ tecnológico no estado do Amapá.

\section{Referências}

ABDI - ASSOCIAÇÃO BRASILEIRA DE DESENVOLVIMENTO INDUSTRIAL; ANPROTEC ASSOCIAÇÃO NACIONAL DE ENTIDADES PROMOTORAS DE EMPREENDIMENTOS DE TECNOLOGIAS AVANÇADAS. Parques tecnológicos no Brasil: estudo, análise e proposições. Brasília, 2008.

ABREU, I. B. L. de et al. Parques tecnológicos: panorama brasileiro e o desafio de seu financiamento. Revista BNDES, [S.I.], v. 45, n. 1, p. 99-154, 2016.

ALMEIDA, M. E. B. Formação de educadores a distância na pós-graduação: potencialidades para o desenvolvimento da investigação e produção de conhecimento. Educação \& Sociedade, São Paulo, v. 33, n. 121, p. 1.053-1.072, 2012.

ANPROTEC - ASSOCIAÇÃO NACIONAL DE ENTIDADES PROMOTORAS DE EMPREENDIMENTOS DE TECNOLOGIAS AVANÇADAS. Estudo, Análise e Proposições sobre as Incubadoras de Empresas no Brasil: relatório técnico/Associação Nacional de Entidades Promotoras de Empreendimentos Inovadores. Ministério da Ciência, Tecnologia e Inovação. Brasília: ANPROTEC, 2012.

AMAPÁ. (Governo do Estado). Lei n. 2.333, de 25 de janeiro de 2018. Dispõe sobre indução $e$ incentivos ao desenvolvimento do Sistema de Ciência, Tecnologia e Inovação, por meio de instrumentos que concedem suporte ao desenvolvimento do ambiente produtivo no Estado do Amapá e dá outras providências. Disponível em: http:/www.al.ap.gov.br/pagina.php?pg=buscar_ legislacao\&n_leiB=2333,\%20de\%2025/04/18. Acesso em: 9 ago. 2019. 
AMAPÁ. (Governo do Estado). O estado e a sua história: histórico. 2009. Disponível em: http:// www4.ap.gov.br/Portal_Gea/historia/dadosestado-historia.htm. Acesso em: 18 maio. 2019.

BELLAVISTA, Joan; SANZ, Luis. Science and technology parks: habitats of innovation: introduction to special section. Science and Public Policy, [S.I.], v. 36, n. 7, p. 499-510, 2009.

BRASIL. Lei n. 13.243, de 11 de janeiro de 2016. Dispõe sobre estímulos ao desenvolvimento científico, à pesquisa, à capacitação científica e tecnológica e à inovação. Diário Oficial da República Federativa do Brasil, Brasília, DF, 12 jan. 2016. Disponível em: http://www.planalto. gov.br/ccivil_03/_Ato2015-2018/2016/Lei/L13243.htm. Acesso em: 9 ago. 2019.

BRASIL. Lei n 8.387, de 30 de dezembro de 1991. Dá nova redação ao $\S 1^{\circ}$ do art. $3^{\circ}$ aos arts. $7^{\circ}$ e $9^{\circ}$ do Decreto-Lei n. 288, de 28 de fevereiro de 1967, ao caput do art. 37 do Decreto-Lei n. .455, de 7 de abril de 1976 e ao art. 10 da Lei n. 2.145, de 29 de dezembro de 1953, e dá outras providências. Disponível em: http://www.planalto.gov.br/ccivil_03/LEIS/L8387.htm. Acesso em: 16 ago. 2019.

BRASIL. Ministério da Ciência, Tecnologia e Inovações e Comunicações (MCTI). Estudo de Projetos de Alta Complexidade: Indicadores de Parques Tecnológicos. Brasília: Centro de Apoio ao Desenvolvimento Tecnológico da Universidade de Brasília (CDT/UnB), 2013. Disponível em: http://www.anprotec.org.br/Relata/PNI_FINAL_web.pdf. Acesso em: 10 jul. 2019.

CDT/UNB - CENTRO DE APOIO AO DESENVOLVIMENTO TECNOLÓGICO DA UNIVERSIDADE NACIONAL DE BRASÍLIA. Estudos de projetos de alta complexidade: indicadores de parques tecnológicos. Brasília: CDT/UNB, 2013.

CDT/UNB - CENTRO DE APOIO AO DESENVOLVIMENTO TECNOLÓGICO DA UNIVERSIDADE NACIONAL DE BRASÍLIA. Estudo de Projetos de Alta Complexidade: indicadores de parques tecnológicos. Brasília: CDT/UNB, 2014.

CLP. Ranking de Competitividade dos Estados 2017. Disponível em: https://www.clp.org.br/ ranking-de-competitividade-dos-estados-2017/. Acesso em: 9 ago. 2019.

CNI - CONFEDERAÇÃO NACIONAL DA INDÚSTRIA. Perfil da Indústria 2017. Disponível em: http://perfildaindustria.portaldaindustria.com.br/estado/ap. Acesso em: 9 ago. 2019

FIGUEIREDO, F. Unidades de conservação vão receber investimentos do Fundo Amapá, 2015. Disponível em: http://arpa.mma.gov.br/unidades-de-conservacao-vao-receber-investimentos-dofundo-amapa. Acesso em: 15 ago. 2019.

FREEMAN, R. E. Strategic management: a stakeholder approach. Massachusetts: Pitman. 1984.

GIL, A. C. Como elaborar projetos de pesquisa. 5. ed. São Paulo: Atlas, 2008.

IASP - INTERNATIONAL ASSOCIATION OF SCIENCE PARKS. [2019]. Disponível em: http://www. iasp.ws. Acesso em: $1^{\circ}$ ago. 2019.

IBGE - INSTITUTO BRASILEIRO DE GEOGRAFIA E ESTATISTICA. Biblioteca. Estatística mensal da produção agrícola, fevereiro 2018. Disponível em: https://biblioteca.ibge.gov.br/index. php/biblioteca-catalogo?view $=$ detalhes $\&$ id=72415. Acesso em: 22 mar. 2018.

IBGE - INSTITUTO BRASILEIRO DE GEOGRAFIA E ESTATISTICA. Biblioteca. Perfil Econômico - Amapá. Departamento de Pesquisa e Estudos Econômicos. Disponível em: https://www.ibge.gov. br/explica/pib.php. Acesso em: 16 jul. 2019. 
MARGARIT, E. Integração do Amapá ao Circuito Produtivo da Soja. Interespaço: Revista de Geografia e Interdisciplinaridade, [S.I.], v. 4, p. 108-119, outubro, 2017.

MIGUEL, L. M. Uso sustentável da biodiversidade na Amazônia brasileira: experiências atuais e perspectivas das bioindústrias de cosméticos fitoterápicos. 2007. 171f. Dissertação (Mestrado em Geografia) - Faculdade de Filosofia, Letras e Ciências Humanas, Universidade de São Paulo, São Paulo, 2007.

MME - MINISTÉRIO DE MINAS E ENERGIA. Setor Mineral do Estado do Amapá. Disponível em: http://www.mme.gov.br/documents/1138775/1732815/Diagn\%C3\%B3stico+do+Setor+Mineral +d $\mathrm{o}+$ Estado+do+Amap\%C3\%A1/baf8b84f-2fa5-4b6e-91c0-ee8bdad01e63?version=1.0. Acesso em: 19 ago. 2018.

PALADINO, G.; MEDEIROS, L. A. Parques tecnológicos e meio urbano: artigos e debates. Brasília: ANPROTEC, 1997. p. 77-84.

PORTO, J. L. R.; BRITO, D. M. C. B. A formação territorial e gestão ambiental no estado do Amapá. In: X ENCONTRO DE GEÓGRAFOS DA AMÉRICA LATINA. 2005. Universidade de São Paulo, São Paulo, SP, 2005. Anais [...] São Paulo, 2005.

ROWE, D. N. E.; COMMINS, N. Success factors for science parks in the developed world and emerging economies. Johannesburg: [s.n.], 2008.

SEBRAE - SERVIÇO BRASILEIRO DE APOIO ÀS MICRO E PEQUENAS EMPRESAS. Site. [2019]. Disponível em: http://www.sebrae.com.br. Acesso em: 18 maio 2019.

SILVA, J. V. M. et al. Zona de Processamento de Exportação: estudo de caso em Cárcere-MT. In: EnANPAD: XXXVIII ENCONTRO DA ANPAD. 2014, Rio de Janeiro, RJ. Anais [...], Rio de Janeiro, 2014. Disponível em: http://www.anpad.org.br/admin/pdf/2014_EnANPAD_APB1090.pdf. Acesso em: 16 jul. 2019.

SPENDOLINI, M. J. Benchmarking. São Paulo: Makroon Books, 1993.

SPOLIDORO, R.; AUDY, J. Parque científico e tecnológico da PUCRS: TECNOPUC. [S.I.]: Edipucrs, 2008.

VILÀ, P. C.; PAGÈS, J. L. Science and technology parks: creating new environments favourable to innovation. Paradigmes, [S.l.], May. 2008. Disponível em: https://www.raco.cat/index.php/ Paradigmes/article/view/226082. Acesso em: $1^{\circ}$ ago. 2019.

VEDOVELLO, C. Aspectos relevantes de parques tecnológicos e incubadoras de empresas. Revista do BNDES, Rio de Janeiro, v. 7, n. 14, p. 273-300, dez. 2000.

ZOUAIN, D. M.; PLONSKI, G. A. Parques Tecnológicos: planejamento e gestão. [S.l.]: Anprotec, 2006.

\section{Sobre os Autores}

\section{Márcio Luis Góes de Oliveira}

E-mail: marcio.oliveira@ifap.edu.br MBA em Gestão Empresarial.

Endereço profissional: IFAP - Instituto Federal do Amapá, BR 210, Km 3, s/n, Brasil Novo, Macapá, AP. CEP: 68909-398. 


\section{José Erivan Ferreira Garçon}

E-mail: j.erivam@hotmail.com

Especialista em Redes de Computadores com ênfase em segurança.

Endereço profissional: PRODAP - Centro de Gestão de Tecnologia da Informação, rua São José, n. 290, Central, Macapá, AP. CEP: 68900-110.

\section{Robson Antonio Tavares Costa}

E-mail: ratcosta@gmail.com

Doutorado em Administração de Empresas.

Endereço profissional: UNIFAP - Universidade Federal do Amapá, Rod. Juscelino Kubitschek, km 02, Jardim Marco Zero, Macapá, AP. CEP: 68903-419. 